\title{
AVALIAÇÃo DA SUBSTITUIÇÃO DE PARCELA DO CIMENTO PORTLAND POR CINZA DE BAGAÇO DE CANA-DE-AÇUCAR NAS PROPRIEDADES MECÂNICAS DE MATERIAIS CIMENTÍCIOS
}

\author{
PLETSCH, ALEXANDER \\ Mestre em Engenharia Civil \\ Unisinos \\ Rio Grande do Sul; Brasil \\ alexanderpletch@yahoo.com.br \\ MENEGOTTO, CAMILA WERNER \\ Graduanda em Engenharia Civil \\ Unisinos \\ Rio Grande do Sul; Brasil \\ camila-wm@hotmail.com
}

\author{
KAZMIERCZAK, CLAUDIO DE SOUZA \\ Doutor em Engenharia Civil \\ Unisinos \\ Rio Grande do Sul; Brasil \\ claudiok@unisinos.br
}

\author{
LUNARDI, MONIQUE PALAVRO \\ Mestranda em Engenharia Civil \\ Unisinos \\ Rio Grande do Sul; Brasil \\ monique.lunardi@hotmail.com
}

\section{RESUMO}

A preocupação com os materiais utilizados para a fabricação de concretos e argamassas vem crescendo gradativamente, em função de fatores como a grande emissão de $\mathrm{CO}_{2}$ que a produção do clínquer transmite para a atmosfera. Por conta disso, vem se estudando alternativas para a substituição de uma parcela do clínquer nos cimentos. A adição pozolânica é estudada a fim de produzir matrizes cimentícias com melhores propriedades mecânicas e maior durabilidade. O Brasil é o maior produtor mundial de cana de açúcar, em que em sua produção resulta-se o bagaço de cana-de-açúcar o qual é reutilizado na própria indústria como combustível para a queima, contudo esse processo gera uma cinza, a qual é descartada pela indústria sucoalcoleira por não ter outro destino. Essa cinza é rica em sílica, podendo ou não se apresentar na forma amorfa, ou seja, potencialmente reativa como material pozolânico. Com o objetivo de avaliar a utilização da cinza amorfa em matrízes cimentícias, foram realizadas as substituições parciais do CP-V ARI nos teores de 5\%, $10 \%$, $20 \%$ e $30 \%$ em três relações a/agl: 0,4, 0,5 e 0,6 com idade de cura até 63 dias. Foi utilizada somente a fração argamassa do concreto, sem agregados graúdos. Foram realizados ensaios de caracterização química da cinza após moagem, como pozolanicidade pelo método de Luxan, índice de atividade pozolânica e posteriormente avaliado a propriedade mecânica de resistência à compressão. Os resultados encotrados mostram que a cinza de bagaço de cana-de-açúcar apresenta resistência à compressão maior que a referência em todas as relações a/agl aos 63 dias, devido a reação pozolânica e ainda, o teor ideal de adição encontrado foi de $20 \%$ de substituição da cinza sem causar perda de resistência mecânica da argamassa.

Palavras-chave: durabilidade, cinza de bagaço de cana-de-açucar, pozolana.

\section{ABSTRACT}

The concerning about the materials used to make concrete and mortars has been growing gradually due to factors such as the large $\mathrm{CO}_{2}$ emission that the clinker production transmit to the atmosphere. Because of this, alternatives are being studied to replace a portion of the clinker in cement. Pozzolanic addition is studied to produce cementitious matrices with better mechanical properties and greater durability. Brazil is the world's biggest producer of sugarcane, in which its production results in sugarcane bagasse which is reused in the industry itself as a fuel for burning, however, this process generates ash, which is discarded by the alcohol industry because it has no other destination. This ash is rich in silica and may or may not be amorphous, potentially reactive as a pozzolanic material. In order to evaluate the use of amorphous ash in concretes, in order to reduce the number of samples, it was decided to work without the coarse aggregate, resulting in the evaluation of mortars, partial substitutions of CP-V ARI were carried out at 5\%, 10\%, 20\% and 30\% in three water/binder ratios: $0.4,0,5$ and 0.6 with cure age up to 63 days. Chemical characterization tests of the ash after grinding were performed, such as pozzolanicity by the Luxan method, pozzolanic activity index and afterward the mechanical property of compressive strength was evaluated. The results show that sugarcane bagasse ash has a higher compressive strength than the reference in all water/binder ratios at 63 days, due to the pozzolanic reaction and the threshold addition content found was $20 \%$ of ash replacement without causing loss of mechanical resistance to mortar.

Keywords: durability, sugarcane bagasse ash, pozzolan. 


\section{INTRODUÇÃO}

O Brasil é considerado o maior produtor de cana-de-açucar, sendo produzidos na safra 2018/19 cerca de 620,44 milhões de toneladas. (CONAB, 2019). O benefiamento da cana-de-açucar gera como derivados o açucar, álcool, energia e acaba gerando um resíduo de cinza de bagaço de cana-de-açucar (CBC), devido ao processo de queima do bagaço nas caldeiras para produção de energia, sendo que para cada tonelada de cana-de-açucar beneficiada cerca de $26 \%$ é bagaço, e quando queimadas uma tonelada de bagaço gera até $7 \mathrm{~kg}$ de cinza residual que ainda não tem destinação correta. (Camara, 2015; Cordeiro, 2006; Pellegrini, 2009). Apesar do bagaço de cana-de-açúcar poder ser utilizado em outras áreas, atualmente no Brasil, cerca de $95 \%$ do bagaço é utilizado no processo de queima para geração de vapor no processo de cogeração de energia. (PAULA, 2006).

A cinza residual é rica em sílica, e se queimada em um processo com controle de qualidade, esta pode se apresentar de forma amorfa, possuindo então possibilidade de apresentar atividade pozolânica quando adicionado as matrízes cimentícias em substituição do cimento portland. (Cordeiro, 2006). O tempo e a temperatura de calcinação são fundamentais para definir se o material ficará no estado amorfo ou cristalino pois é isso que irá definir se a cinza irá reagir com os compostos de hidratação do cimento. (BAHURUDEEN, SANTHANAM, 2015; CORDEIRO et al. 2009; GANESAN et al. 2007; OLIVEIRA, 2014; PAULA, 2006).

As características das cinzas dependem da sua queima, sendo que as modificações ocorrem de acordo com a temperatura atingida. Até $100{ }^{\circ} \mathrm{C}$ ocorre a evaporação da água presente no bagaço, em torno de $350^{\circ} \mathrm{C}$ inicia-se a queima do material volátil, entre as temperaturas de $400{ }^{\circ} \mathrm{C}$ a $500^{\circ} \mathrm{C}$ o carbono presente é oxidado sendo que após essa etapa a cinza tornase rica em sílica amorfa. Temperaturas acima de $700{ }^{\circ} \mathrm{C}$ podem levar a formação do quartzo e/ou outras formas cristalinas, sendo que temperaturas de queima acima de $800^{\circ} \mathrm{C}$, a sílica presente na cinza é principalmente cristalina. (PAULA,2006). Alguns autores concordam que cinzas calcinadas a $500{ }^{\circ} \mathrm{C}$ resultam em maior reatividade com o hidróxido de cálcio, porém, essas cinzas podem possuir uma grande quantidade de carbono, resultante da queima incompleta e de outros produtos orgânicos. (PAIVA, 2016). A microestrutura da cinza visualizada a partir de ensaio de microscopia eletrônica de varredura (MEV) mostra que a estrutura é caracterizada por elementos fibrilares e porosos conforme Figura 1. (Câmara, 2015).

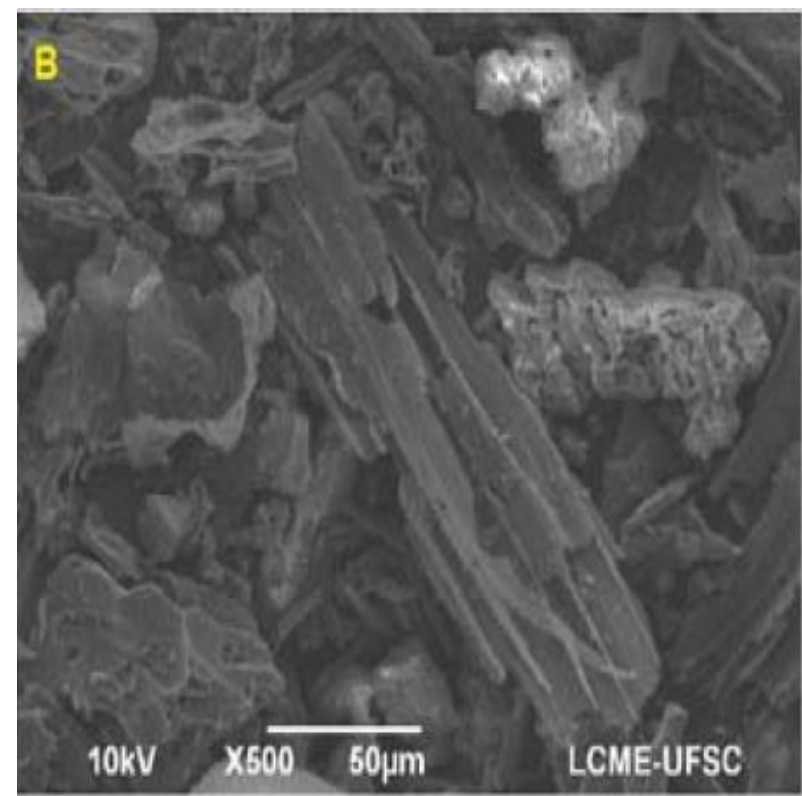

Figura 1: Morfologia das partículas fibrosas

Para que um material seja classificado como pozolânico, a NBR 12653 (ABNT, 2014) estabelece exigências físicas e químicas, como o valor mínimo de $50 \%$ para a soma dos teores de $\mathrm{SiO}_{2}+\mathrm{Al}_{2} \mathrm{O}_{3}+\mathrm{Fe}_{2} \mathrm{O}_{3}$ para classe E, e o mínimo de $70 \%$ para classe $\mathrm{NeC}$.

Com a utilização de adições minerais em concretos, tem-se inúmeros benefícios em relação ao concreto fresco e endurecido, sendo alguns fatores: a melhora da trababilidade, o aumento da plasticidade sem aumentar o consumo de água, modificar o tempo de pega, reduzir a exsudação e segregação, pode-se ter o aumento da resistência final e a 
diminuição dos poros, melhoria da resistência à fissuração térmica em razão ao baixo teor de hidratação, a resistência por ataque de sulfatos, redução da reação álcali-agregado e da corrosão das armaduras, sendo que a melhoria desses fatores reflete diretamente na durabilidade do material. (POGGIALI, 2010).

A utilização das pozolanas nas misturas são responsáveis pela alteração na velocidade de reação, que geralmente é maior, consomem hidróxido de cálcio e auxiliam na distribuição do tamanho dos poros. Ainda, as pozolanas geram vantagens econômicas pois o consumo de cimento Portland é diminuído, além disso gera economia de energia, pois os materiais pozolânicos são energeticamente mais econômicos em relação ao clínquer do cimento Portland. O uso de pozolanas, contribui também para a redução dos resíduos industriais poluidores. (OLIVEIRA E BARBOSA, 2006).

O cimento Portland é um dos materiais mais utilizados no mundo, no entanto, no seu processo de fabricação, consome recursos naturais não renováveis e energia, sendo que a produção de cimento é responsável por cerca de 7\% das emissões globais de $\mathrm{CO}_{2}$, de acordo com dados World Business Council For Sustainable Development - WBCSD (2018). Por este motivo, diversos materiais estão sendo estudados como substituição parcial do cimento, entre eles, a cinza de bagaço-decana de açucar. (PAIVA,2016).

O presente estudo tem por objetivo a avaliação das propriedades mecânicas utilizando a fração argamassa do concreto com CBC em teores de substituição de $0,5,10,20$ e $30 \%$ em relação ao cimento portland, com três porosidades diferentes (a/c: 0,4, 0,5 e 0,6) visando a possibilidade de utilização deste resíduo como material cimentício suplementar.

\section{MATERIAIS E MÉTODOS}

Para a realização da presente pesquisa utilizou-se o Cimento Portland V - ARI, por conter pequenos teores de adições de material carbonático (até 5\% da massa total). O agregado miúdo utilizado foi de origem natural quartzosa, obtendo um módulo de finura na ordem de 2,33. A fim de garantir a trabalhabilidade da mistura, utilizou-se aditivo superplastificante. O estudo apresentou cinco variações de adição da cinza de bagaço de cana-de-açúcar, em teores de 0\%, 5\%, 10\%, 20\% e $30 \%$. O resíduo primeiramente passou por um processo de moagem, utilizando o moinho de bolas vertical, durante duas horas, até que apresentasse um D50 inferior a $10 \mu \mathrm{m}$, em seguida realizou-se os ensaios de caracterização da mesma quanto a pozolanicidade, característica química e física, conforme apresentado na Tabela 1. Para cada teor de adição foram produzidas misturas com proporções a/agl de 0,4, 0,5 e 0,6. A cinza utilizada nesta pesquisa foi coletada em industria localizada na cidade de Porto Xavier no Estado do Rio Grande do Sul.

Tabela 1 - Caracterização da cinza de bagaço de cana-de-açúcar

\begin{tabular}{cccc}
\hline Propriedade & Ensaio & Resultado & Norma \\
\cline { 2 - 4 } Pozolanicidade & Índice de atividade pozolanica & Apresentou um teor de 95\% & NBR 5752 (ABNT, 2014) \\
\cline { 2 - 4 } & Condutividade elétrica & $\begin{array}{c}\text { Alta pozolanicidade em 50\% das } \\
\text { amostras e moderada } \\
\text { pozolanicidade em 50\% das } \\
\text { amostras }\end{array}$ & Método de Lúxan (1989) \\
& FRX & Encontrados Si, Fe, Al, K & $\begin{array}{c}\text { Fluôrescencia de Raios } \\
\text { Caracterização Química }\end{array}$ \\
\cline { 2 - 4 } & Perda ao fogo & $23,1 \%$ de massa, alta perda ao fogo & CEMP 120 \\
\hline \multirow{2}{*}{ Caracterização Física } & Massa especifíca & $2,33 \mathrm{~g} / \mathrm{cm}^{3}$ & NBR NM 23 \\
\cline { 2 - 4 } & Granulometria & D50 $5,89 \mu \mathrm{m}$ & Difração a laser \\
\hline
\end{tabular}

Nota-se que o resíduo em estudo apresentou elevada atividade pozolânica, atendendo ao especificado pela norma. Desta forma, foram moldados corpos de prova prismáticos com dimensões de 6x6x18 cm, com um traço de 1:3 (cimento/aglomerante:areia). Nota-se que para o trabalho, foi utilizada somente a fração argamassa do concreto, e, portanto, as dimensões do molde seguiu o especificado pela NBR 5738 (ABNT, 2016) que especifica que o molde deve possuir duas arestas com mesma dimensão e a outra com no minimo 3 vezes a dimensão da aresta menor. Na Tabela 2 , está apresentado a relação de material utilizado para cada teor de substituição, sendo o referencia (REF), com $0 \%$ de adição. Na Figura 2 há a distribuição granulométrica da cinza obtida por granulometria a laser a qual apresentou $\mathrm{D}_{50}$ de $5,89 \mu \mathrm{m}$. 
Tabela 2 - Proporções de materiais utilizados na moldagem

\begin{tabular}{cccccccc}
\hline Traço & Cim. $(\mathbf{g})$ & CBC (g) & Areia (g) & Água (g) & a/agl & Aditivo (g) & Aditivo (\%) \\
\hline REF & 6500 & - & 19500 & 2600 & 0,4 & 46 & $0,70 \%$ \\
REF & 6500 & - & 19500 & 3250 & 0,5 & 33 & $0,50 \%$ \\
REF & 6500 & - & 19500 & 3900 & 0,6 & 0,00 & $0,00 \%$ \\
$5 \%$ CBC & 6175 & 242,37 & 19500 & 2566,95 & 0,4 & 61 & $0,95 \%$ \\
$5 \%$ CBC & 6175 & 242,37 & 19500 & 3208,68 & 0,5 & 42 & $0,65 \%$ \\
$5 \%$ CBC & 6175 & 242,37 & 19500 & 3850,42 & 0,6 & 0,00 & $0,00 \%$ \\
$10 \%$ CBC & 5850 & 484,73 & 19500 & 2533,89 & 0,4 & 63 & $1,00 \%$ \\
$10 \%$ CBC & 5850 & 484,73 & 19500 & 3167,37 & 0,5 & 44 & $0,70 \%$ \\
$10 \%$ CBC & 5850 & 484,73 & 19500 & 3800,84 & 0,6 & 00 & $0,00 \%$ \\
$20 \%$ CBC & 5200 & 969,46 & 19500 & 2467,79 & 0,4 & 100 & $1,20 \%$ \\
$20 \%$ CBC & 5200 & 969,46 & 19500 & 3084,73 & 0,5 & 49 & $0,80 \%$ \\
$20 \%$ CBC & 5200 & 969,46 & 19500 & 3701,68 & 0,6 & 00 & $0,00 \%$ \\
$30 \%$ CBC & 4550 & 1454,20 & 19500 & 2401,68 & 0,4 & 300 & $1,60 \%$ \\
$30 \%$ CBC & 4550 & 1454,20 & 19500 & 3002,10 & 0,5 & 66 & $1,10 \%$ \\
$30 \%$ CBC & 4550 & 1454,20 & 19500 & 3602,52 & 0,6 & 30 & $0,50 \%$ \\
\hline
\end{tabular}

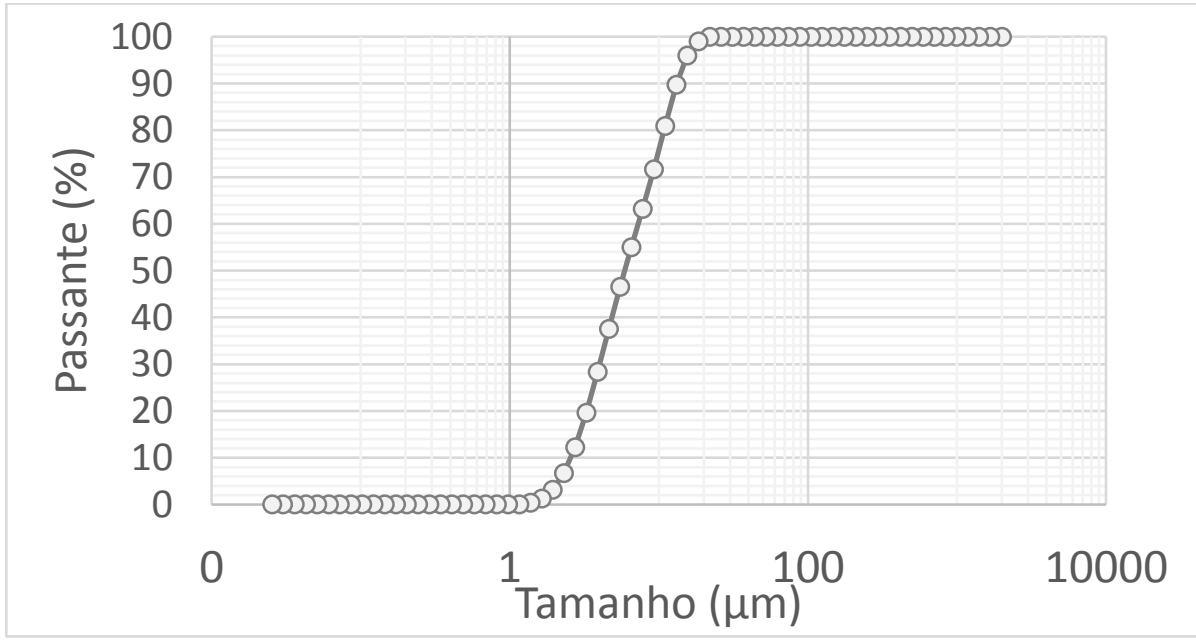

Figura 2: Distribuição granulométrica da cinza de bagaço de cana-de-açúcar

Com o intuito de padronizar a trabalhabilidade, a porcentagem de aditivo apresentado na Tabela 2, foi estabelecido de acordo com ensaios previamente realizados, utilizando o método de Flow Table, da NBR 13276 (ABNT, 2016), em que todos os traços apresentaram resultados semelhantes, resultando em uma média de espalhamento de $231 \mathrm{~mm}$.

A resistência à compressão foi determinada aos 7, 28 e 63 dias, sendo ensaiados 3 corpos de prova por idade.

O processo de mistura consistiu no uso de uma argamassadeira vertical, com tempo de mistura aproximadamente de 5 minutos. Após a moldagem, os corpos de prova foram vibrados e colocados em uma câmara úmida, com temperatura controlada de $21{ }^{\circ} \mathrm{C} \pm 2{ }^{\circ} \mathrm{C}$. Ao concluir um período de 24 horas, os corpos de prova foram desformados, identificados e colocados submersos em água e cal.

Considerando que os corpos de prova eram prismáticos, o ensaio de resistência à compressão ocorreu de forma distinta. Primeiramente foi rompido a amostra por tração na flexão, no centro, obtendo duas frações, aos quais foram ensaiadas, com o auxílio de duas pastilhas metálicas de $6 \times 6 \mathrm{~cm}$, colocadas na parte superior e inferior do corpo de prova, com o intuito de restringir a área e padronizar o ensaio, desta forma obteu-se 2 resultados de resistência à compressão por corpo de prova. 


\section{RESULTADOS E DISCUSSÕES}

Os resultados de resistência mecânica à compressão dos corpos de prova estão apresentados na Tabela 3 que apresenta os resultados para todas as idades ensaiadas. Considerando o elevado número de resultados originados, e a fim de simplificar as análises, realizou-se uma média que representa cada amostra.

Tabela 3 - Resultados da resistência à compressão para todas as idades em análise

\begin{tabular}{ccccccccccc}
\hline Traços & $\begin{array}{c}\text { Relação } \\
\text { a/agl }\end{array}$ & $\begin{array}{c}\mathbf{7} \\
\text { dias }\end{array}$ & $\begin{array}{c}\text { Desvio } \\
\text { padrão }\end{array}$ & $\begin{array}{c}\text { Coeficiente } \\
\text { de variação }\end{array}$ & $\begin{array}{c}\mathbf{2 8} \\
\text { dias }\end{array}$ & $\begin{array}{c}\text { Desvio } \\
\text { padrão }\end{array}$ & $\begin{array}{c}\text { Coeficiente } \\
\text { de variação }\end{array}$ & $\begin{array}{c}\mathbf{6 3} \\
\text { dias }\end{array}$ & $\begin{array}{c}\text { Desvio } \\
\text { padrão }\end{array}$ & $\begin{array}{c}\text { Coeficiente } \\
\text { de variação }\end{array}$ \\
\hline REFERÊNCIA & 0,4 & 39,28 & 3,95 & 0,10 & 42,68 & 8,07 & 0,19 & 46,58 & 14,38 & 0,31 \\
REFERÊNCIA & 0,5 & 24,28 & 1,07 & 0,04 & 33,51 & 1,28 & 0,04 & 38,16 & 1,69 & 0,04 \\
REFERÊNCIA & 0,6 & 20,63 & 2,57 & 0,12 & 24,30 & 1,75 & 0,07 & 35,85 & 2,20 & 0,06 \\
$5 \%-$ CBC & 0,4 & 31,51 & 4,53 & 0,14 & 38,65 & 4,41 & 0,11 & 52,63 & 3,23 & 0,06 \\
$5 \%-$ CBC & 0,5 & 29,29 & 4,57 & 0,16 & 35,05 & 10,87 & 0,31 & 47,41 & 2,63 & 0,05 \\
$5 \%-$ CBC & 0,6 & 25,28 & 5,28 & 0,21 & 29,11 & 4,18 & 0,14 & 43,60 & 4,47 & 0,10 \\
$10 \%-$ CBC & 0,4 & 27,81 & 1,52 & 0,05 & 37,92 & 4,09 & 0,11 & 53,18 & 2,12 & 0,04 \\
$10 \%-$ CBC & 0,5 & - & - & - & 31,69 & 1,21 & 0,04 & 52,31 & 1,83 & 0,04 \\
$10 \%-$ CBC & 0,6 & 25,27 & 1,70 & 0,07 & 26,94 & 2,07 & 0,08 & 38,87 & 0,52 & 0,01 \\
$20 \%-$ CBC & 0,4 & 30,75 & 6,34 & 0,21 & 36,59 & 7,71 & 0,21 & 51,61 & 3,00 & 0,06 \\
$20 \%-$ CBC & 0,5 & 26,83 & 2,56 & 0,10 & 32,76 & 5,92 & 0,18 & 46,79 & 1,17 & 0,03 \\
$20 \%-$ CBC & 0,6 & 17,63 & 3,37 & 0,19 & 24,79 & 1,39 & 0,06 & 38,69 & 1,97 & 0,05 \\
$30 \%$ - CBC & 0,4 & 29,03 & 3,18 & 0,11 & 30,83 & 5,24 & 0,17 & 40,93 & 1,87 & 0,05 \\
$30 \%-$ CBC & 0,5 & 23,26 & 3,38 & 0,15 & 30,98 & 6,70 & 0,22 & 34,84 & 4,73 & 0,14 \\
$30 \%$ - CBC & 0,6 & 16,30 & 2,32 & 0,14 & 25,14 & 1,41 & 0,06 & 31,28 & 2,35 & 0,08 \\
\hline
\end{tabular}

Com o intuito de compreender o comportamento da cinza de bagaço de cana no composto cimentício, as análises ocorrem separadamente para cada relação a/agl.

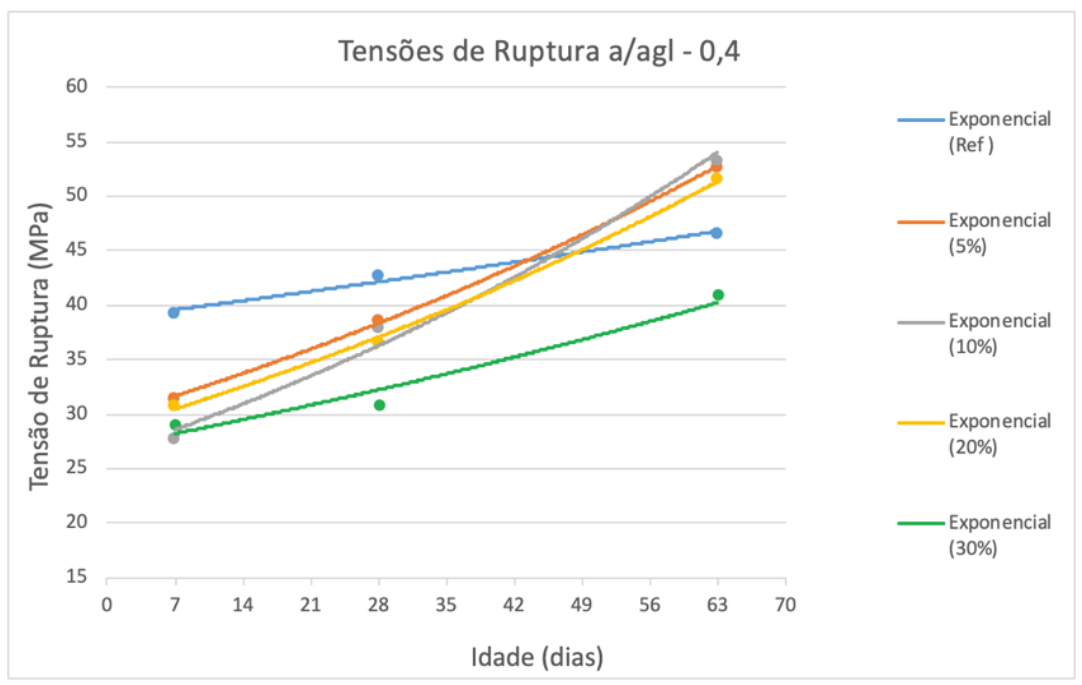

Figura 3: Resistência à compressão na relação a/agl 0,4 para todas as idades em análise

Primeiramente analisando a relação a/agl 0,4, conforme apresentado no Figura 3 é possível notar que o composto cimentício referência, ou seja, com teor de cinza de $0 \%$ apresentou melhores resultados na idade de 7 dias e 28 dias do que os demais. Entretanto aos 63 dias observa-se que os compostos com teores de 5\%, $10 \%$ e $20 \%$ apresentaram uma resistência à compressão superior à referência, este fenômeno pode ser compreendido devido ao fato das pozolanas com alto teor de sílica começarem a sua reação de hidratação em uma idade mais tardia do que o cimento, e também pelo efeito filer que ocorre no composto, visto que a cinza possui menor granulometria do que os outros materiais utilizados, dessa 
forma há uma área de contato superior. Ainda, percebe-se que no teor de cinza de 30\% não houve um ganho de resistência que superasse os demais, concluindo que, conforme visto na literatura, esta faixa de substituição é elevada, prejudicando a resistência da argamassa. Em seguida, analisou-se a relação a/agl 0,5, conforme apresentado no Figura 4.

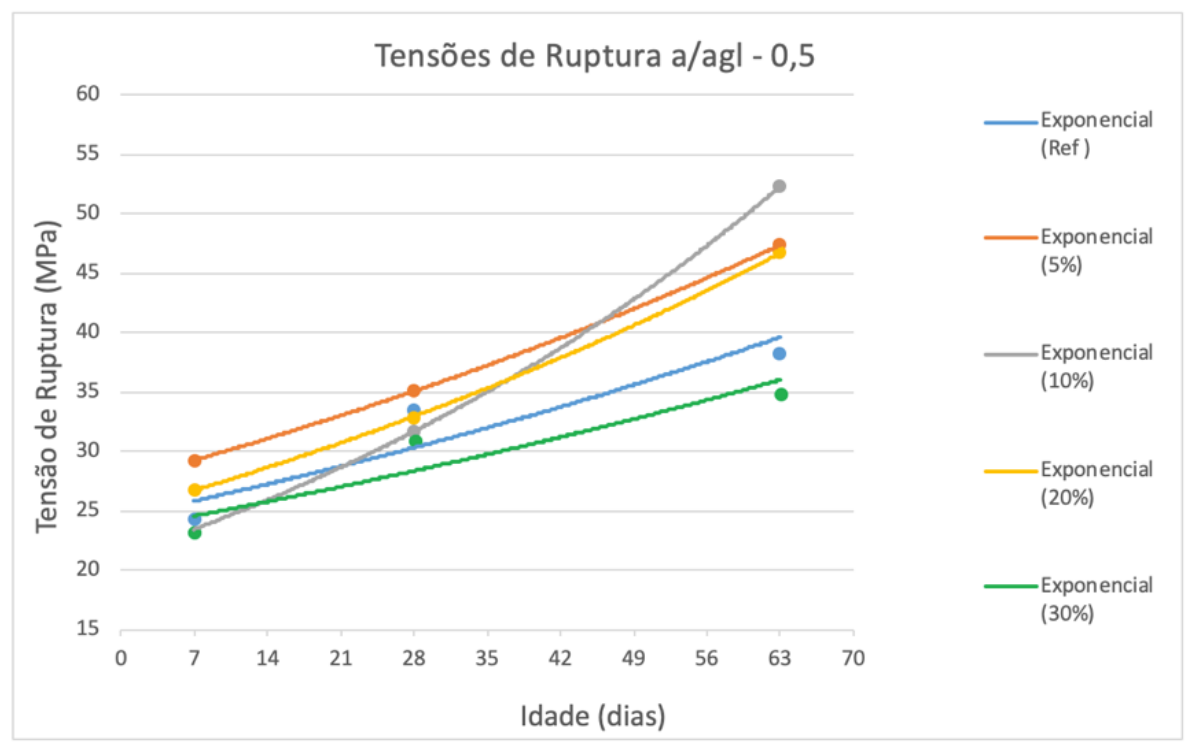

Figura 4: Resistência à compressão na relação a/agl 0,5 para todas as idades em análise

Para a relação a/agl 0,5, observa-se que os teores de substituição de cinza de $5 \%$ e $20 \%$ são superiores à referência ao longo de todo o período de análise. Aos 63 dias o teor de 10\% de substituição também apresenta um ganho de resistência significativo, superando a argamassa de referência. O teor de cinza de $30 \%$ de substituição manteve o mesmo comportamento apresentado na relação a/alg 0,4, enfatizando que é um elevador teor, diminuindo a resistência. A relação a/agl 0,6 é apresentada na Figura 5.

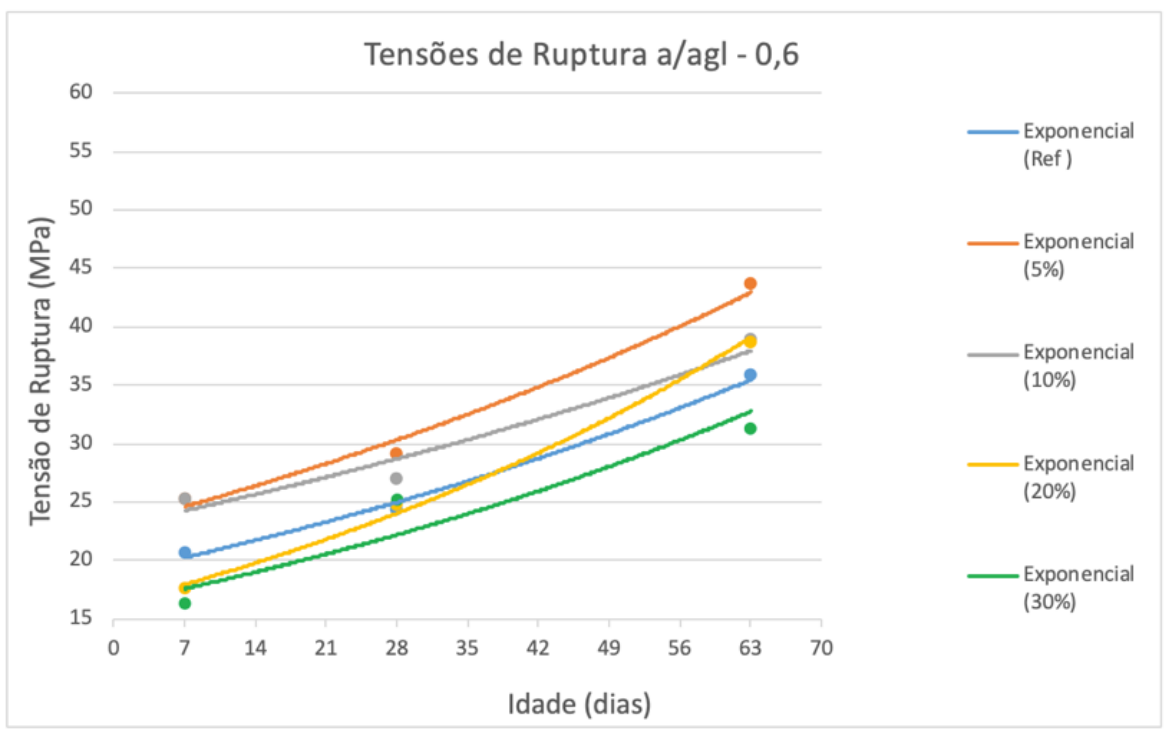

Figura 5: Resistência à compressão na relação a/agl 0,6 para todas as idades em análise

Para a relação a/agl 0,6, nota-se que os teores de cinza de 5\% e 10\% de substituição apresentaram resistência superior à referência aos 7 dias e 28 dias, contudo conforme visto nas relações apresentadas anteriormente aos 63 dias a resistência dos teores 5\%, 10\% e 20\% superaram a referência. Fica confirmado que após os 28 dias, a pozolana hidrata e melhora as propriedades do composto cimentício. Já o teor de 30\% manteve o mesmo comportamento anteriormente citado, demonstrando que é uma elevada porcentagem de substituição, e que teores acima de $20 \%$ de substituição não apresentam melhorias que viabilizem esse teor. 


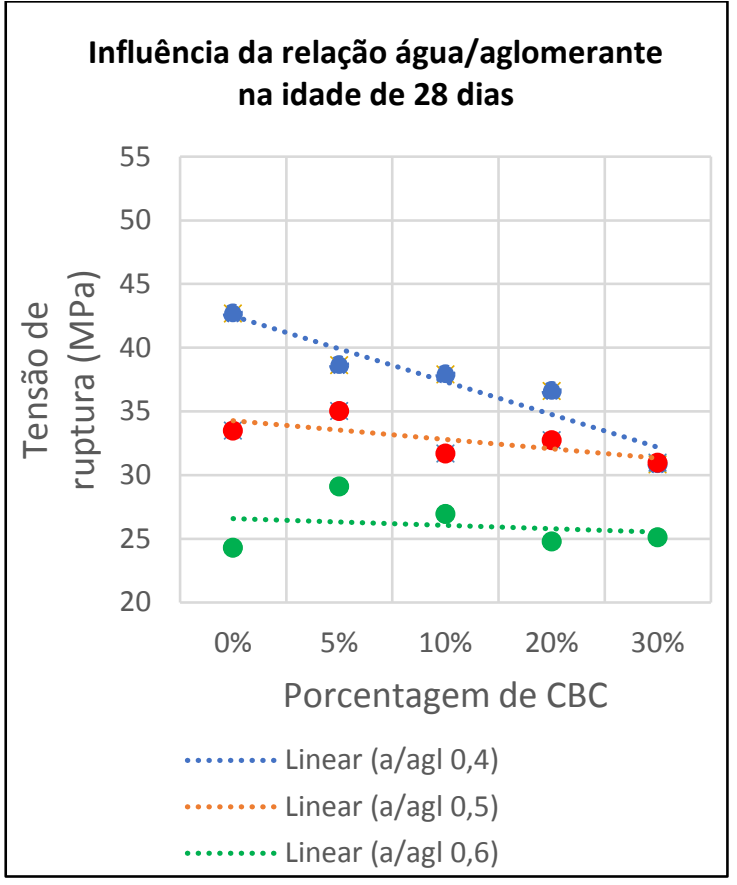

Figura 6: Influência da relação a/c na resistência à compressão dos traços

\section{Influência da relação água/aglomerante na idade de 63 dias}

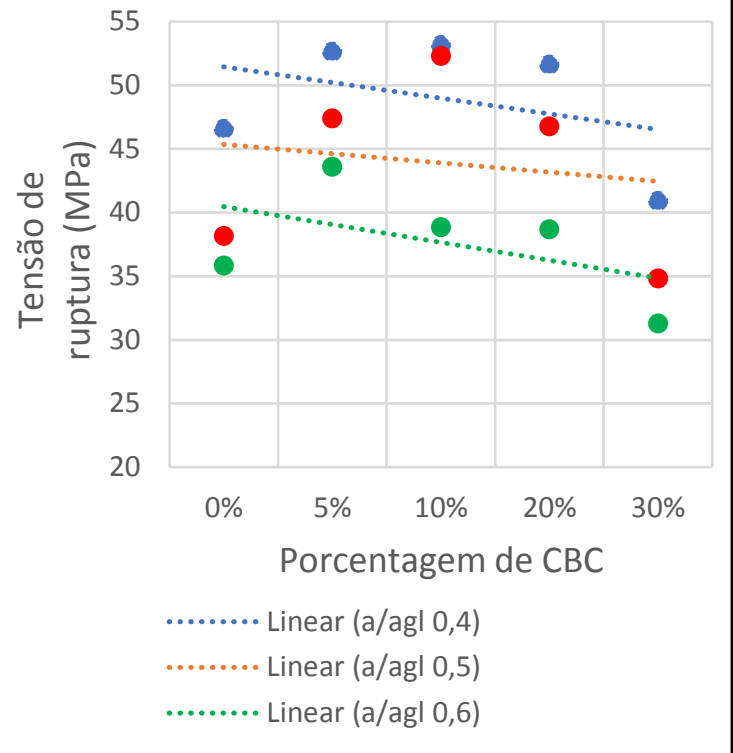

a) Influência da relação a/agl na resistência mecânica aos 28 dias b) Influência da relação a/agl na resistência mecânica aos 63 dias

Ao analisar a influência da relação a/c nas resistências à compressão dos corpos de prova aos 28 e 63 dias, apresentados na Figura 6 (a) e (b), é possível observar que em todos os casos a relação a/c 0,4 apresentou resistência superior as demais, isso porque há uma menor porosidade da matriz cimentícia.

Aos 63 dias, as linhas de tendência apresentam uma maior proporcionalidade e resistências muito superiores às encontradas aos 28 dias, o que demonstra a reatividade da pozolana nos traços, e que ao longo do tempo as relações a/c tendem a seguir o mesmo comportamento ainda que em faixas de resistência diferentes. Ainda assim, nota-se que o teor de substituição de $30 \%$ é o que apresentou menor resistência em todas as relações a/c acima de 63 dias, o que mais uma vez sugere um teor máximo de substituição de $20 \%$.

\section{CONCLUSÕES}

(a) A resistência à compressão dos compostos com adições de cinza, se mostraram superiores à dos traços sem adições, em especial para os teores de $5 \%$ e $10 \%$ para as relações a/agl 0,5 e 0,6 ;

(b) A relação a/agl 0,4 em conjunto com o teor de cinza de $20 \%$ apresentou os melhores resultados;

(c) O teor máximo de substituição de cimento Portland por cinza de bagaço de cana-de-açúcar é de $20 \%$ em massa, sem causar perda na resistência mecânica;

\section{REFERÊNCIAS}

BAHURUDEEN, A.; SANTHANAM, M. Influence of different processing methods on the pozzolanic performance of sugarcane bagasse ash. Cement and Concrete Composites, v 56, p. 23 - 45, 2015.

CÂMARA, E. Efeitos da Substituição Parcial de Agregados Miúdos Por Cinza Residual do Bagaço da Cana-deAçúcar no Processo de Hidratação do Cimento. Tese de Doutorado. 2015. 186 f. Universidade Federal de Santa Catarina, Florianópolis, SC, 2015. 
CONAB - Companhia Nacional de Abastecimento. Perfil do Setor do Açúcar e do Etanol no Brasil - Edição para safra 2018/19. Disponível em: < https://www.conab.gov.br/info-agro/safras/cana>. Acesso em: 26 de maio de 2019.

CORDEIRO, G. C. Utilização de Cinzas do Bagaço de Cana-de-açúcar e da Casca de Arroz como Aditivos Minerais em Concreto. 2006. 405 f. Tese de Doutorado Universidade Federal do Rio de Janeiro, RJ, 2006.

GANESAN, K.; RAJAGOPAL, K.; THANGAVEL, K. Evaluation of bagasse ash as supplementary cementitious material. Cement \& Concrete Composites, v. 29, p. 515-524, 2007.

OLIVEIRA, J. F. de. Obtenção de sílicas mesoporosas altamente ordenadas a partir das cinzas da casca de arroz e do bagaço da cana-de-açúcar. 2014. 156 f. Dissertação de Mestrado. Universidade de São Paulo, São Paulo, SP, 2014.

PAIVA, O. A. Durabilidade de concretos contendo cinza do bagaço da cana-de-açúcar. 2016. 309 f. Tese de Doutorado. Universidade Federal do Rio de Janeiro, Rio de Janeiro, RJ, 2016.

PAULA, M. O. Potencial da cinza do bagaço da cana-de-açúcar como material de substituição parcial de cimento Portland. 2006. 77 f. Dissertação de Mestrado. Universidade Federal de Viçosa, Viçosa, MG, 2006

PELLEGRINI, L. F. Análise e otimização termo-econômico-ambiental aplicada à produção combinada de açúcar, álcool e eletricidade. 2009. 349 f. Tese de Doutorado. Escola Politécnica da Universidade de São Paulo, São Paulo, SP, 2009. 